\title{
Posicionamento dos partidos políticos brasileiros na escala esquerda-direita: dilemas metodológicos e revisão da literatura ${ }^{5}$
}

The positioning of Brazilian political parties on the left-right scale: methodological dilemmas and literature review

\section{Introdução}

Em artigo publicado anteriormente, buscou-se investigar qual o posicionamento do Partido dos Trabalhadores (PT) e do Partido da Social Democracia Brasileira (PSDB) na escala esquerda-direita, utilizando como parâmetro as eleições de 2014 e, como método, a abordagem oferecida pelo Comparative Manifesto Project (JORGE et al., 2018). Neste novo trabalho, a intenção é outra: adensar a discussão metodológica contida no primeiro artigo. Dessa forma, pretende-se apresentar uma nova contribuição para o diálogo acerca da ideologia dos partidos políticos brasileiros e sobre as melhores estratégias para mensurá-la (MELO; CÂMARA, 2012; LUCAS;

\footnotetext{
1 Professor do Departamento de Ciências Sociais e do Programa de Pós-Graduação em Ciências Sociais do Instituto de Ciências Humanas e Sociais da Universidade Federal Rural do Rio de Janeiro (ICHS/UFRRJ), Rio de Janeiro, RJ, Brasil. E-mail: <vljorge@uol.com.br>

2 Professora do Departamento de Ciências Sociais da Pontifícia Universidade Católica do Rio de Janeiro (PUC-Rio), Rio de Janeiro, RJ, Brasil. E-mail: <alessandramtf@puc-rio.br>

3 Professora do Programa de Pós-Graduação em Ciências Sociais da Universidade Federal Rural do Rio de Janeiro (UFRRJ), Rio de Janeiro, RJ, Brasil. E-mail: <alessandramtf@gmail.com>, $<$ mayragoulart@gmail.com>

4 Professora do Departamento de Ciência Política do Instituto de Filosofia e Ciências Sociais da Universidade Federal do Rio de Janeiro (IFCS/UFRJ), Rio de Janeiro, RJ, Brasil.. E-mail: $<$ mayragoulart@gmail.com>

5 Os autores são gratos pelas contribuições e críticas feitas à primeira versão deste artigo pelos avaliadores. Revista Brasileira de Ciência Política, no 33. e227686, 2020, pp 1-44. 
SAMUELS, 2011; MADEIRA; TAROUCO, 2011; TAROUCO; MADEIRA, 2013a, 2013b; POWER; ZUCCO JR., 2009; MAINWARING; MENEGUELLO; POWER, 2000; MAINWARING, 1991).

Além de introdução e conclusão, este artigo contém outras quatro seções. Na primeira, discorreremos sobre tais estratégias esclarecendo por que esta é uma agenda de pesquisa válida para aqueles que almejam lançar luz sobre o comportamento dos atores políticos.

Na segunda seção, discutiremos a importância do programa de governo como objeto de estudo de ideologias de candidatos e partidos políticos. Justificamos o uso desses documentos argumentando que sua relevância decorre de serem manifestações públicas de candidatos e partidos políticos acerca de questões de interesse público e nacional. Embora não seja nosso propósito aqui tratar de como o resultado de análises do conteúdo de programas de governo podem ser comparados com o de outras pesquisas, ressaltamos, ao final dessa seção, que esse tema é de enorme interesse para o debate acerca de metodologia desenvolvidas para mensurar a ideologia de candidatos e partidos políticos.

$\mathrm{Na}$ terceira seção, tratamos da apresentação da história do Comparative Manifesto Project (CMP-MARPOR) e da metodologia por eles desenvolvida para, entre outras coisas, permitir que o pesquisador (a) posicione os partidos políticos em um ponto da escala esquerda-direita e (b) realize uma análise comparativa entre partidos políticos de diferentes países e/ou épocas. Julgamos que, dessa forma, será possível apresentar uma introdução para leitores brasileiros não familiarizados com essa abordagem, permitindo-os compreender como e por que se desenvolveu essa metodologia e, portanto, avaliar sua adequação ou não, a depender dos objetivos estimados para a abordagem do caso em questão: o sistema partidário brasileiro.

Ainda na terceira seção, vamos explicitar os procedimentos que os pesquisadores interessados devem ser capazes de realizar para poder utilizar a referida metodologia, codificando o texto dos programas de governo a serem analisados e, assim, prepará-los 
para que outros pesquisadores possam usar o índice Rile ou algum outro índice criado pelo CMP-MARPOR. ${ }^{6}$ Essa explicação é conveniente para que se esclareça os cuidados tomados a fim de evitar ou minimizar: (a) os erros de codificação e (b) a subjetividade na codificação das sentenças. Como será argumentado ao longo da seção, isso é o que permite que a referida metodologia forneça uma base empírica sólida, a qual, caso acompanhada da análise qualitativa dos programas e da leitura da bibliografia pertinente acerca dos partidos políticos brasileiros, pode servir de alicerce para conclusões comparativas futuras.

Por fim, explicamos o que é o índice Rile $\left(I_{r}\right)$ e como ele é calculado. Esse esclarecimento é necessário uma vez que nosso propósito geral é apresentá-lo como alternativa para produzir inferências acerca do posicionamento ideológico de agremiações políticas, situando-as em uma escala esquerda-direita passível de facilitar o estabelecimento de comparações e deslocamentos espaciais e temporais. Com isso, almejamos reforçar as virtudes analíticas da literatura brasileira que, de modo geral, atenta para a singularidade do nosso sistema político (CARREIRÃO, 2014; GOMES, 2013; TAROUCO; MADEIRA, 2013a, 2013b; LEONI, 2011; MELO, 2010; AMORIM, 2000), reforçando, porém, a importância da dimensão comparativa oferecida pelo método do CMP-MARPOR (BUDGE; MEYER, 2013, p. 56-86). ${ }^{7}$

$\mathrm{Na}$ quarta e última seção, serão discutidos, em interseção com os tópicos anteriores, alguns apontamentos para futuras investigações sobre o método analisado. Nessa seção apresentamos as reformulações e adaptações incorporadas à metodologia do CMP ao longo do processo de ampliação de seu banco de dados, primeiramente

6 Além do índice Rile, que é apresentado neste artigo, os criadores do Comparative Manifesto Project elaboraram outros cinco índices. Três fazem referência ao âmbito econômico e dois são referentes a política externa, quais sejam: Planeco - Planned Economy; Markeco - MarketEconomy; Welfare - Welfare References; Intpeace - International Peace; Europ - European Integration Index (BUDGE et al., 2006, p. 143)

7 Anteriormente conhecido como Projeto Manifesto Research Group/Comparative Manifestos (MRG/ CMP), o Manifesto Research on Political Representation (MARPOR) é responsável por administrar o Manifesto Project Database (MPD) que contém análises de conteúdo quantitativo de programas de governo de partidos de mais de 50 países. O banco de dados pode ser acessado em https://manifesto-project.wzb.eu. 
aos países do Leste Europeu e, em um segundo momento, para o subcontinente latino-americano. Convém frisar que, em todas essas seções, dialogamos com a literatura especializada, sobretudo com aquela que questiona o uso dessa metodologia para auferir o posicionamento ideológico dos partidos, particularmente no que diz respeito à América Latina. Por fim, demonstrando a hipótese acerca da utilidade da metodologia por nós escolhida, iremos apresentar os resultados obtidos por meio de sua aplicação, mapeando o posicionamento dos principais partidos políticos brasileiros e observando sua movimentação na escala ideológica ao longo de todas as eleições presidenciais realizadas no Brasil sob a égide da Constituição de 1988.

\section{Comportamento político e ideologia política: um debate metodológico}

O que determina as escolhas dos atores políticos? Quais são as variáveis centrais a serem consideradas quando analisamos o comportamento de partidos, candidatos e lideranças políticas? Desde Anthony Downs (1999), a teoria da escolha racional se debruça sobre os condicionantes da ação política e desenvolve ferramentas analíticas para responder a estas perguntas. Desse modo, consideram-se três modelos que funcionam como tipos ideais do comportamento partidário: vote-seeking parties, office seeking parties e policy-seeking parties (STROM, 1990). O primeiro modelo aparece já na contribuição seminal de Downs e considera os partidos como atores cujo único objetivo seria a maximização do apoio eleitoral com o propósito de adquirir o controle do governo (STROM, 1990, p. 566-567).

O segundo modelo entende que os partidos têm como propósito central não os votos, mas a maximização do controle sobre os cargos políticos (offices), tendo em vista os benefícios a eles atribuídos (usualmente adjetivados na literatura internacional como pork 
barrel). ${ }^{8} \mathrm{O}$ terceiro modelo (policy-seeking) indica que o principal objetivo dos partidos é implementar políticas públicas, que, por sua vez, são concebidas a partir de valores e visões de mundo, organizados e sumariados através de ideologias.

No tocante ao comportamento dos atores políticos, os três modelos são complementares. A distribuição de cargos e a garantia de uma base eleitoral são condições para a implementação de políticas públicas, que, quando bem implementadas, tendem a aumentar a satisfação dos cidadãos e, por conseguinte, as chances de vitória eleitoral. Por este motivo, os três objetivos (policies, offices e votes) devem ser levados em conta em qualquer abordagem empírica acerca do comportamento político de partidos e coalizões realmente existentes (BUDGE; LAVER, 1986, p. 485). Como ressalva Downs (1999) em seu trabalho seminal acerca do tema, ao disputar votos e cargos, os partidos precisam diferenciar-se uns dos outros também sob uma perspectiva ideológica. Sendo assim, mesmo quando compreendemos seu comportamento através dos modelos vote e office-seeking, a ideologia é uma variável relevante.

\section{Ideologias políticas e estratégias de mensuração}

O conceito de ideologia política é alvo de uma longeva controvérsia que passa ao largo dos objetos deste artigo. Nas palavras de Dijk (2015, p. 54 apud MEDEIROS, 2018, p. 58), "ideologias são sistemas de crenças compartilhadas por grupos com a finalidade de promover seus interesses e orientar suas práticas sociais e políticas". Entendidas como "atalhos mentais" que simplificam uma miríade de valores, anseios, perspectivas e visões por vezes contraditórias e múltiplas nas formulações individuais, as ideologias políticas serão aqui consideradas sob uma perspectiva instrumental. Sob esse prisma, os conceitos de direita e esquerda tornam-se elementos centrais na análise do comportamento de eleitores e eleitos, uma vez que simplificam uma miríade de posições, identidades e valores,

8 Pork barrel é uma expressão recorrentemente utilizada na literatura internacional para tipificar o particularismo legislativo de parlamentares que ambicionam medidas distributivas que maximizem o voto dos beneficiários (BAIÃO; COUTO; JUCÁ, 2018, p. 52). 
facilitando a compreensão e a dinâmica interna de cada sistema político, em especial, dos mais complexos (MEDEIROS, 2018; FREIRE, 2006).

Em seu interessante trabalho sobre a evolução das ideologias políticas ao longo do século XX, Knight (2006) sustenta que, apesar das variadas definições, é possível pensar em consensos mínimos, afirmando que quase todas as teorizações consideram as noções de coerência, estabilidade e contraste. As ideologias funcionam, portanto, como mecanismos de coesão entre convicções que passam a ser relacionadas entre si, relativamente persistentes no tempo e opostas a outros sistemas de crenças (SILVA, 2017, p. 25).

No entanto, apenas quando são definidas como sistemas estruturados de valores que se manifestam por meio de formulações explícitas e conscientes, as ideologias se tornam um objeto de análise passível de ser mensurado. É essa a orientação seguida nesta pesquisa. Por este motivo, porém sem ignorar sua polissemia, reduziremos o escopo semântico do conceito para analisar três dimensões nas quais ele pode ser mobilizado: "(i) enquanto instrumento de classificação das posições políticas dos diferentes partidos (e/ou candidatos/eleitos); (ii) como código de comunicação entre forças políticas, meios de comunicação social e eleitores e finalmente, (iii) enquanto instrumento de orientação dos eleitores na interpretação dos fenômenos políticos e na tomada de decisões" (FREIRE, 2006, p. 31).

Desdobrados esses três eixos, é possível observar um conjunto de definições que conformam o núcleo semântico do conceito de ideologia, entre as quais podemos listar: $i$ ) um sistema de crenças/ ideais políticos; ii) um conjunto de propostas políticas orientadas para a ação; iii) as ideias da classe dirigente ou de determinada classe ou grupo social (FREIRE, 2006, p. 35). Cada definição, por sua vez, demanda um tipo de metodologia quando o objetivo é fazer inferências acerca do comportamento político de atores reais. O que não significa, contudo, que as diferentes abordagens não precisem ser combinadas. 
Sob um ponto de vista puramente esquemático, podemos considerar que, se o propósito for analisar a ideologia em seu conteúdo, isto é, enquanto pensamento político, um tipo de abordagem teórico filosófico é mais adequado. No entanto, se o objeto for o comportamento dos atores, é interessante recorrer a outras estratégias. Metodologias voltadas à análise de conteúdo e de discurso, por exemplo, são utilizadas quando o propósito é observar ou mensurar a ideologia política de um determinado ator tendo em vista o modo como ele se apropria dela, como é o caso da análise de votações nominais, de programas de governo, de projetos de lei (políticas públicas) e de discursos de modo geral. Nesses casos, todavia, é necessário definir conteúdos semânticos como indícios de posicionamento ideológico, o que, por sua vez, recai em questões teórico-filosóficas acerca dos componentes de cada orientação.

Outra estratégia utilizada com o propósito de mensurar a ancoragem social das ideologias pela população são as pesquisas de opinião (surveys). Se o objeto são os cidadãos comuns, as pesquisas tendem a utilizar uma amostra abrangente e representativa do tecido social ou do eleitorado. Se, por outro lado, o objeto é um grupo específico, no caso de líderes partidários, membros do Legislativo ou do Executivo, por exemplo, o universo amostral é constituído pelo próprio objeto, o que poderia dar a impressão de que pesquisas dessa natureza chegariam a conclusões inequívocas e menos subjetivas.

Entretanto, uma vez que o comportamento político dos atores se determina também por fatores estratégicos (como nos modelos vote-seeking and office seeking), a mensuração do componente ideológico de suas ações através da autodefinição também pode trazer resultados não tão confiáveis. Em outros termos, perguntar aos políticos eleitos como eles se definem ideologicamente pode não ser a melhor opção - ou uma opção que não precisaria ser complementada por outras estratégias -, na medida em que tal definição pode ser forjada por interesses ou estratégias momentâneas individuais ou partidárias. Por este motivo, surveys realizados com políticos dificilmente consistem apenas no autoposicionamento no espectro 
ideológico, inquirindo também o posicionamento dos entrevistados em face de questões econômicas, políticas e sociais que se acreditam representativas de suas orientações ideológicas.

Outra forma de contornar o problema é deixar que o posicionamento seja mensurado por especialistas, supostamente capazes de situá-los no espectro ideológico com precisão e rapidez na classificação. Os chamados expert surveys também contornam outros obstáculos encontrados por aqueles que realizam pesquisas com os políticos e os cidadãos, sobretudo no tocante à dificuldade destes atores em compreender as perguntas, as escalas e as métricas utilizadas (BOLOGNESI; BABIRESKI; MACIEL, 2019).

No caso do Brasil, mesmo reconhecendo a dificuldade de mensurar a ideologia política de atores políticos em um sistema multipartidário particularmente fragmentado, as pesquisas sobre o tema têm aumentado em número e na abrangência das metodologias utilizadas (SCHEEFFER, 2018; CODATO; BERLATTO; BOLOGNESI, 2018; MELO, 2015; TAROUCO; MADEIRA, 2013a, 2013b; DIAS; MENEZES; FERREIRA, 2012; MADEIRA; TAROUCO, 2011; DANTAS; PRAÇA, 2010; WIESEHOMEIER; BENOIT, 2009; ZUCCO JR., 2009; POWER; ZUCCO JR., 2009; BRAGA, 2007; CARREIRÃO, 2006; KINZO, 2005; RODRIGUES, 2002a, 2002b; COPPEDGE, 1997 apud BOLOGNESI; BABIRESKI; MACIEL, 2019). Em comum, esses trabalhos compartilham o reconhecimento da importância do estudo do tema e da localização dos partidos dentro de um espectro ideológico comum, uma vez que esse esforço permite observar a diferença entre eles, mas também suas mudanças ao longo do tempo. A despeito dessa convergência, esses esforços se distinguem no tocante à estratégia metodológica utilizada. Os partidos políticos podem ser classificados por:

- especialistas (WIESEHOMEIER; BENOIT, 2009; TAROUCO; MADEIRA, 2015; MACIEL; ALARCON; GIMENES, 2018);

- seus próprios membros (POWER; ZUCCO JR., 2009; ZUCCO JR., 2011); 
- eleitores (LAVAREDA, 1999; SINGER, 2000; CARREIRÃO, 2015; KINZO, 2005; OLIVEIRA; TURGEON, 2015, SILVA, 2017);

- seus discursos e programas de governo (TAROUCO; MADEIRA, 2013b; BABIRESKI, 2014a, 2014b; BOLOGNESI; BABIRESKI; MACIEL, 2019);

- projetos de lei e políticas públicas que apresentam (DIAS; MENEZES; FERREIRA, 2012);

- seus comportamentos em votações nominais e em face de questões estratégicas (LEONI, 2002; HAGOPIAN; GERVASONI; MORAES, 2009; SCHEEFFER, 2018; SHALDERS, 2017);

- sua composição social (RODRIGUES, 2002a, 2002b; RIBEIRO; BOLOGNESI, 2018).

Diante dessa variedade de metodologias, emergem algumas perguntas que certamente precisarão ser respondidas:

1) Em que medida é possível comparar a posição ideológica de um partido mensurada pelos programas de governo com a forma como os eleitores percebem os partidos ou com a autoclassificação dos membros dos partidos no parlamento?

2) O que a possível discrepância ou congruência entre esses dados pode dizer sobre o sistema partidário brasileiro?

3) Qual a correlação entre as tendências na opinião pública e as movimentações dos partidos a partir da análise dos programas de governo?

Não temos a intenção de tratar dessas questões aqui. Nosso propósito, neste artigo, é mais modesto: i) apresentar o índice criado pelo CMP-MARPOR para mensurar e localizar a ideologia de partidos políticos na escala esquerda-direita; ii) discutir seu processo de adaptação e expansão para a América Latina; e, por fim, iii) avaliar sua aplicabilidade ao contexto brasileiro. Entendemos que esta é uma reflexão inicial que visa contribuir para futuras pesquisas comparativas. Acreditamos que, apesar das dificuldades apontadas por alguns analistas (ADAMS; EZROW, 2009; BENOIT; MICHAEL; MIKHAYLOV, 2009; TAROUCO; MADEIRA, 2013a, 2013b), a 
proposta metodológica do CMP-MARPOR poderá contribuir para se alcançar uma visão mais ampla do sistema político brasileiro.

\section{Programas de governo como objeto de estudo}

A metodologia desenvolvida pelo CMP-MARPOR requer, como uma de suas etapas, a codificação dos programas de governo apresentados, a cada eleição, pelos candidatos e/ou partidos políticos que pleiteiam conquistar o Poder Executivo nacional. O pressuposto desse tipo de análise é que esses documentos são um objeto que pode auxiliar na identificação da posição dos candidatos/ partidos políticos ao longo do eixo esquerda-direita. Mas, se esses documentos são o objeto de estudo que permitirá situar um respectivo candidato/partido político em algum ponto desse eixo, acreditamos que devemos esclarecer, ainda que sucintamente, a relevância dos programas de governo como fonte de informação para esses estudos.

É plausível supor que, embora, de modo geral, os eleitores não leiam os programas de governo, essa relação ocorra em função do que é veiculado pelos meios de comunicação. Ademais, para além dessa relevância na configuração da relação entre representantes e representados, isto é, na seleção das elites políticas, também é possível supor que os programas auxiliem na organização dessas elites no interior do Estado. Como tal, fornecem um substrato necessário para a formação de coalizões ou para negociações parlamentares e presidenciais, ou mesmo para coordenar as ações individuais de ministros de um governo, podendo agir como o único guia de coordenação geral para a política disponível.

Ainda que não se tenha evidências robustas de que os programas de governo (a) estruturam políticas públicas, (b) sejam usados para negociar coalizões de governo ou (c) sejam parâmetros na tomada de decisão dos eleitores, isso não diminui a importância do uso desses documentos como estratégia para mensurar ideologias políticas. Os programas de governo são manifestações públicas de candidatos e de partidos políticos e, como qualquer outro dado 
observacional feito por atores políticos, podem nos ajudar a elucidar o posicionamento desses atores no eixo esquerda-direita.

Para nossa discussão, contudo, o mais importante é como o resultado da análise do conteúdo desses documentos se relaciona e pode ser comparada a outras pesquisas sobre a ideologia dos partidos políticos e, assim, contribuir, por exemplo, para se compreender melhor o sistema político brasileiro.

\section{Aplicando o método: a codificação dos documentos}

Nesta seção iremos apresentar o método que utilizamos para mensurar a ideologia dos partidos políticos brasileiros, deixando claro que esta estratégia prevê, como uma etapa necessária, sua combinação com outras metodologias, em especial com a análise qualitativa dos documentos.

Textos políticos são a fonte mais comum de evidências sobre a política, mas, ao mesmo tempo, são também a fonte mais negligenciada de análise, se consideradas as análises quantitativas. Porém, de que forma seria possível adotar textos enquanto dados? Nesse sentido, o esforço se baseou numa crítica que conformou e reforçou um método, cujo propósito é evitar bias e falta de representatividade para as evidências catalogadas em pesquisas (BUDGE et al., 2006).

Esse esforço se estendeu à própria forma pela qual se procede à leitura e produção dos relatórios sobre o que se escolhe pesquisar. Análises quantitativas sobre palavras-chave, sentenças ou expressões podem ser realizadas em concordância com procedimentos específicos em relação a todo um conjunto de documentos relevantes analisados. Tal proposta provê uma base consistente para a abordagem de problemas de seleção, graus de confiança e validade ou, pelo menos, conforma um processo pelo qual tais ações são especificadas com clareza. A ideia de analisar diferentes programas de governo segundo sua codificação a partir de quase-sentenças deu origem ao que hoje se conhece como MPDb - The Manifesto Project Database.

A quase-sentença é a menor unidade de análise dentro de um processo de codificação de documentos, sendo definida como: 
um argumento ou frase que é a expressão verbal de uma ideia ou significado. É frequentemente delimitada em um texto por vírgulas, ponto e vírgula ou dois pontos. Sentenças longas podem conter mais de um argumento, o que necessita dividi-lo em quase-sentenças (BUDGE et al., 2006, p. xvi, tradução nossa). ${ }^{9}$

A proposta é que cada quase-sentença, a partir de cada documento analisado, possa ser classificada por meio de um mesmo sistema de categorias políticas relacionadas, de acordo com um conjunto de regras e instruções próprias. Cada decisão de codificação é gravada em uma cópia original, e assim pode ser revisada e mesmo corrigida caso se faça necessário. A sistematização, organização ou distribuição das sentenças em categorias é o que distingue um documento do outro. Movimentos observáveis na comparação das distribuições marcam mudanças políticas ao longo do tempo, e destacam diferenças em um documento de um determinado partido político, quando comparado a outros.

O manual entregue aos codificadores garante a flexibilidade de usos que o CMP-MARPOR pode oferecer para pesquisas sobre partidos políticos. Segundo Budge e seus companheiros, a metodologia do CMP-MARPOR estima relações tanto no que se refere a famílias tradicionais de partidos políticos (traditional family parties) quanto aos posicionamentos que esses tomaram mais recentemente nas disputas políticas (BUDGE et al., 2013, p. 64). Acredita-se, pois, que a metodologia pode inclusive refinar ambas as abordagens, além de permitir a identificação de nichos partidários e oferecer uma alternativa às abordagens teóricas que desejem testar suas propostas por meio da observação dos padrões de movimentação ideológica dos partidos políticos (BUDGE et al., 2013, p. 65).

9 No original: "'quasi-sentence' is defined as an argument or phrase which is the verbal expression of one idea or meaning. It is often marked off in a text by commas or (semi-)colons. Long sentences may contain more than one argument so that they need to be broken up into quasi-sentences" (BUDGE et al., 2006, p. xvi). 
Antes de iniciar, de fato, a codificação dos programas de governo, os encarregados são treinados. Os membros do CMP-MARPOR consideram que os codificadores desempenham um papel crucial no processo de produção de dados e, nesse sentido, são a chave para garantir a continuidade e confiabilidade na produção do banco de dados. O ponto de partida é que eles sejam nativos da língua empregada para redigir os manifestos a serem analisados (BUDGE et al., 2013, p. 174).

Não se trata, contudo, de ser apenas um nativo no idioma. $\mathrm{O}$ segundo princípio observado é o grau de escolaridade ou experiência profissional equivalente em algum campo relevante de pesquisa sobre partidos políticos. Adicionalmente, codificadores são considerados especialistas em um determinado país, e a expectativa é que contribuam com riqueza de informações específicas sobre seus contextos nacionais. Quando pessoas qualificadas são identificadas, elas passam por uma série de atividades de treinamento desenvolvidas para introduzir as duas principais partes e ações do processo de codificação: a unificação dos manifestos em uma versão de quase-sentenças individuais e a alocação dos códigos em categorias. Unificar e agrupar em categorias são o coração do processo de produção de dados do CMP-MARPOR.

Algumas partes do texto, como estatísticas, tabelas e títulos de seção não são consideradas como parte textual da plataforma política analisada e, dessa forma, não contam como quase-sentenças. Partes introdutórias que incluam exortações realizadas pelos respectivos líderes políticos também são desconsideradas, tendo em vista que o tipo-ideal da plataforma de dados considera apenas afirmações mandatórias em nome dos partidos. Todas as demais partes dos documentos analisados são consideradas enquanto base para análise. $\mathrm{O}$ número total de unidades de análise que servirá de base para o cálculo das frequências será igual ao número total de quase-sentenças identificadas (BUDGE et al., 2006, p. 167). Desse modo, como será desenvolvido adiante, essa abordagem evita eventuais vieses na seleção de temas e trechos a serem considerados 
ou desconsiderados, permitindo que a atenção do pesquisador se distribua de maneira igualitária sobre a totalidade do documento.

A codificação, enquanto quadro de classificação padrão, permite três tipos de comparação: i) mudanças entre posições políticas ou ênfases ao longo do tempo em partidos específicos; ii) diferenças entre posições políticas ou ênfases entre partidos; e iii) diferenças entre países. ${ }^{10}$ Os dados básicos procurados para permitir tais comparações são as proporções que os diferentes programas de governo devotam para cada uma das áreas de problemas padronizadas.

Para que a comparação seja possível, é necessária a padronização. Foi com esse intuito que o CMP-MARPOR definiu 56 categorias, entre as quais 12 foram divididas em duas ou mais subcategorias. Essas categorias e subcategorias, por sua vez, foram agrupadas em sete domínios, a saber:

1) relações internacionais, que contém dez categorias e duas subcategorias;

2) liberdade e democracia, que agrupa quatro categorias e seis subcategorias;

3) sistema político, que abrange cinco categorias e seis subcategorias;

4) economia, que reúne dezesseis categorias e duas subcategorias;

5) estado de bem-estar e qualidade de vida, que comporta sete categorias;

6) estrutura da sociedade, que possui oito categorias e quatorze subcategorias; e, por fim,

7) grupos sociais, com seis categorias e duas subcategorias.

Segundo Budge e seus companheiros (2013), ao adotar tal método para a análise de documentos individualmente considerados, os resultados podem ser mais bem interpretados ao se comparar seus valores com os de outros partidos em uma mesma eleição, ou mesmo em relação a um mesmo partido ao longo de uma série histórica de eleições (FRANZMANN, 2013, p. 229). A

10 Um exemplo da comparação entre diferentes países são os trabalhos de Babireski (2014a, 2014b). 
vocação da metodologia aqui apresentada é comparativa e é através desse tipo de esforço que ela alcança seu potencial heurístico.

Tal comparação pode revelar diferenças entre eleições que tiveram altas concentrações em alguma categoria nos programas de governo em relação a outras com menor concentração. Ao combinar essas descrições com informações externas, o que se consegue obter como resultado são análises causais e não simplesmente uma descrição de valores singulares. Nesse sentido, o CMP-MARPOR viabiliza a produção de inferências e diagnósticos sobre grupos emissores de determinadas mensagens políticas ao longo do tempo.

Cabe salientar que há situações em que o codificador não poderá utilizar as categorias acima apresentadas. Nesses casos, ele deverá empregar o código 000 (no meaningful category applies). Segundo o Manifesto coding instructions, o codificador deverá empregá-lo nestas duas situações: "1- quando a sentença for desprovida de sentido e não puder ser codificada pelo contexto; 2- quando a sentença se referir a uma posição política que não está incluída entre as categorias apresentadas (WERNER; VOLKENS; LACEWELL, 2015, p. 12, tradução nossa).

Não obstante, é importante esclarecer que o manual apresentado pelo CMP-MARPOR aos codificadores aconselha a utilização do código 000 apenas em última instância. A recomendação, diante de uma frase que não se encaixe claramente em uma das categorias é que a codificação seja feita pelo contexto. Daí a importância na seleção da equipe de codificadores que deverão ser capazes de interpretar o documento, utilizando como tela de fundo seus conhecimentos sobre a realidade e a história política do país. Ademais, há códigos cuja utilização pressupõe essas capacidades de modo ainda mais explícito. É o caso das categorias 101 e 102, que não têm necessariamente valor por si mesmas, mas são mobilizadas como um marcador usado para separar relações bilaterais determinadas por questões conjunturais, de relações de caráter mais estrutural e longevo. ${ }^{11} \mathrm{~A}$ ideia por trás das categorias de special relations é evitar que esse tipo de relacionamento

11 Por esse motivo, as sentenças codificadas como 101 e 102 são excluídas do cálculo da posição direita-esquerda, que será objeto da próxima seção deste trabalho. 
especial seja incluído em outras categorias como 104, 105, 107 e 110, que revelam posicionamentos políticos particulares em temáticas de âmbito internacional. No caso brasileiro, nossa equipe foi responsável por definir e enviar ao CMP-MARPOR uma lista dos países com os quais o Brasil se relaciona de maneira especial, no caso: Paraguai, Portugal e Estados Unidos.

\section{Esquerda e direita segundo o CMP-MARPOR: o índice Rile}

Norberto Bobbio afirma que os termos "esquerda" e "direita" são antitéticos, excludentes e exaustivos (BOBBIO, 1995, p. 31-32). Sob este prisma, ao distinguir entre esquerda e direita, não estamos excluindo a possibilidade de um partido político ocupar uma posição intermediária entre um polo e outro, que denominamos geralmente de "centro". O reconhecimento dessa possibilidade nos permite distinguir um centro mais próximo ou mais distante dos extremos, seja à esquerda ou à direita. Assim, podemos falar de uma centro-esquerda ou centro-direita. É possível, ainda, identificar uma esquerda ou uma direita moderada, que tende ao centro, e uma esquerda ou direita extremada, que se distancia do centro. Por esses motivos, utilizamos, neste e em outros trabalhos, a ideia de "eixo" ou "escala" esquerda-direita.

A metodologia desenvolvida pelo CMP-MARPOR fornece uma operacionalização independente que possibilita identificar algumas categorias como de direita e de esquerda. Nesse caso, o posicionamento do partido político na escala esquerda-direita é obtido por meio do cálculo de um índice, conhecido como Rile. Desenvolvida originalmente pelo Manifesto Research Group (MRG), esta é uma das escalas indicadoras mais conhecidas e usadas pelos pesquisadores que utilizam os dados do CMP-MARPOR (BUDGE; MEYER, 2013, p. 85). O índice é construído a partir das 56 categorias utilizadas no processo de codificação concebido pelo CMP-MARPOR, das quais incorpora duas importantes características:

a) são heavily saliency-based, ou seja, se orientam com referência ao conteúdo de um tópico específico mais do que à posição a favor ou contra algo, ou seja, a ênfase relativa em 
um argumento diante da totalidade dos outros (o número de vezes em que um tópico aparece) será mais determinante do que a veemência com que esta argumentação é empreendida (BUDGE; MEYER, 2013, p. 86); e

b) são baseadas em agrupamentos de assuntos presentes tanto nos manifestos ingleses quanto nas plataformas partidárias americanas dos anos 1920-1976 (BUDGE; FARLIE, 1977, p. 421-433 apud BUDGE; MEYER, 2013, p. 86; ROBERTSON, 1976). Tais agrupamentos foram refinados em discussões do MRG para que pudessem ser aplicadas nos mais de 20 países democráticos existentes no mundo após a II Guerra Mundial, entre 1979 e 1980.

Nesse sentido, essas categorias são produto de uma experiência histórica particular, embora tenham se mostrado aptas para a produção de generalizações, possivelmente porque os problemas enfrentados pelos formuladores de políticas nas sociedades de massa modernas sejam similares em nível básico (BUDGE; MEYER, 2013, p. 86). Por conseguinte, essas duas características geraram muita polêmica. As controvérsias decorreram, em especial, da natureza dedutiva e apriorística que norteia o método classificatório desenvolvido pelo MRG, que contrasta com as abordagens indutivas que tendem a predominar na Ciência Política.

O índice Rile (Ir) é obtido pela aplicação da fórmula:

$$
I r=\frac{R-L}{R+L+O}
$$

Após a análise de todo programa de governo, os percentuais de categorias são somados de modo a se obter o percentual total de categorias de direita, esquerda e outros. $O R$ corresponde à soma dos percentuais de 13 categorias identificadas como de direita (right): 104 (military: positive), 201 (freedom and human rights: positive), 203 (constitutionalism: positive), 305 (political authority: positive), 401 (free market economy), 402 (incentives: positive), 407 (protectionism: negative), 414 (economic orthodoxy), 505 (welfare state limitation), 601 (national way of life: positive), 603 (traditional 
morality: positive), 605 (law and order) e, por fim, 606 (civic mindedness: positive).

O exame das 13 categorias supracitadas leva a concluir que elas se referem a propostas apresentadas pelo candidato/partido político que atribuem importância:

1) às Forças Armadas e, consequentemente, à necessidade de se investir para a manutenção e o fortalecimento dessas instituições a fim de que possa garantir a segurança e a defesa externa;

2) à liberdade individual e aos direitos humanos e civis, o que significa, por um lado, a defesa da liberdade de expressão, de imprensa, de possuir propriedade e de dispor dela como quiser, de reunião etc. e, por outro, a crítica ao controle burocrático e à coerção do Estado nas esferas políticas e econômicas;

3) à preservação da constituição;

4) à política econômica favorável às empresas e às instituições financeiras e que vise a redução do déficit público, o que implica, entre outras coisas, em limitar os gastos do Estado com serviços sociais ou segurança social;

5) à redução ou eliminação do protecionismo e, consequentemente, à defesa do livre comércio;

6) aos apelos patrióticos gerais e à história da nação;

7) aos valores morais tradicionais e religiosos;

8) à execução mais rigorosas da lei e ações conjuntas mais duras contra o crime doméstico; e

9) a apelos gerais à solidariedade nacional e à necessidade de união nacional.

Em suma, o critério para se identificar partidos políticos de direita consiste em encontrar, no programa de governo do candidato, soluções para problemas políticos que, por um lado, priorizam a defesa das chamadas liberdades negativas, a conservação do status quo, o estímulo ao sistema capitalista e a preservação da moral cristã. Por outro lado, são desfavoráveis a políticas que tenham como meta o aumento dos gastos públicos com o intuito de promover a igualdade social. 
O $L$, por sua vez, é obtido a partir da soma dos percentuais das 13 categorias identificadas como de esquerda (left): 103 (anti-imperialism: positive), 105 (military: negative), 106 (peace), 107 (internationalism: positive), 202 (democracy), 403 (market regulation), 404 (economic planning), 406 (protectionism: positive), 412 (controlled economy), 413 (nationalisation), 504 (welfare state expansion) 506 (education expansion) e, finalmente, 701 (labour groups: positive).

Já a análise das 13 categorias identificadas como de esquerda nos leva a concluir que estas se referem a propostas apresentadas pelo candidato/partido político que atribuem importância:

1) à condenação do comportamento imperial e/ou de um Estado que exerce forte influência comercial, militar ou política sobre outros países;

2) à crítica às Forças Armadas e/ou ao uso do poder militar na resolução de conflitos e, consequentemente, à valoração da paz ou de meios pacíficos como forma de superação de crises;

3) à necessidade de priorizar a cooperação internacional ou, em outras palavras, a defesa do multilateralismo;

4) à valorização da democracia como única forma de governo aceitável;

5) à política econômica favorável à intervenção do governo com o intuito de criar um mercado mais competitivo e justo, ao planejamento duradouro, à proteção do mercado interno, ao controle de preços e à preservação do controle de empresas e terras;

6) à necessidade de aumentar os gastos públicos com o intuito de expandir o sistema de ensino e/ou introduzir, manter ou expandir qualquer serviço público ou de seguridade social; e

7) à defesa da classe trabalhadora, incluindo desempregados em geral, e dos sindicatos e todas as demais associações de trabalhadores.

Portanto, o critério para se identificar partidos políticos de esquerda consiste em observar, no programa de governo do candidato, soluções para problemas políticos que, por um lado, priorizem a defesa da democracia e da soberania, o apelo às negociações 
diplomáticas e ao multilateralismo, o estímulo à intervenção do Estado e a defesa da classe trabalhadora. Por outro lado, são desfavoráveis a políticas que tenham como meta o uso da força como meio de resolver os conflitos e a promoção do chamado Estado mínimo com o intuito de aumentar as liberdades negativas.

Além do uso das 26 categorias supracitadas, a aplicação do índice Rile exige também o uso das demais 30 que não foram identificadas como sendo de esquerda ou de direita. ${ }^{12}$ Essas categorias são identificadas como outras (other) e, na fórmula, o $O$ corresponde à soma dos percentuais dessas categorias. Portanto, quando analisado o texto, tanto categorias identificadas como "não-esquerda" quanto as identificadas como "não-direita" têm participação na determinação do resultado final. Isto porque, mais do que a ênfase em uma determinada proposta ou orientação, é sua importância relativa diante dos demais temas abordados no programa que determinará seu posicionamento na escala ideológica - o que está associado à virtude holística da metodologia, que considera a totalidade de temas delineados em cada documento.

$O$ índice Rile reflete tendências sobre toda a extensão de informações acerca dos posicionamentos partidários neutros, assim como de esquerda e de direita. A escala conforma, assim, um sumário geral sobre o perfil político de um determinado partido sobre todas as questões, mais do que apenas um reflexo de posicionamento entre direita e esquerda. Desse modo, como nos esclarece Budge e seu companheiros (2013), quanto mais sentenças forem tipificadas como "outros" mais o partido terá seu posicionamento ideológico convergindo para o centro.

Cabe considerar, contudo, que esta escala ideológica foi concebida de forma apriorística a partir de tópicos que eram relacionados

12 As categorias abarcam, ainda, subcategorias. A categoria 103 inclui as subcategorias 103.1 (state centred anti-imperialism) e 103.2 (foreign financial influence); 201 abarca as subcategorias 201.1 (freedom) e 201.2 (human rights); 202 inclui 202.1 (general: positive), 202.2 (general: negative), 202.3 (representative democracy: positive), 202.4 (direct democracy: positive); 305 reúne 305.1 (political authority: party competence), 305.2 (political authority: personal competence), 305.3 (political authority: strong government), 305.4 (former elites: positive), 305.5 (former elites: negative), 305.6 (rehabilitation and compensation); 601 envolve 601.1 (general) e 601.2 (immigration: negative); 606 inclui 606.1 (general) e 606.2 (bottom-up activism). 
à teoria política e ao discurso ideológico do início do século XX (BUDGE; MEYER, 2013, p. 89; BUDGE et al., 2013, p. 2-3). Esse debate tendia a opor preocupações com a "ordem tradicional das coisas", a "segurança interna e externa" e a "liberdade", que eram associadas à posição ideológica de direita, a preocupações com "bem-estar geral", "intervenção estatal para garanti-lo" e o "internacionalismo pacifista", que eram, por sua vez, relacionados à posição ideológica de esquerda. As referências teóricas para a configuração das categorias indicativas de posicionamento à esquerda são as obras de Karl Marx e seus desdobramentos teóricos. A produção teórica de Benjamin Disraeli, T. H. Green e Herbert Spencer influenciaram na definição das categorias indicativas de posicionamento à direita (BUDGE; MEYER, 2013, p. 89; BUDGE et al., 2013, p. 2-3).

O desdobramento teórico dessas considerações pelos herdeiros do legado marxista e do pensamento conservador orientaria, portanto, o agrupamento das categorias segundo grandes temas. Tais referências, contudo, não nos parecem suficientes, uma vez que os critérios utilizados para tipificação das categorias não são devidamente explicitados, assim como sua fundamentação teórica. Mas, embora teoricamente superficiais, elas são úteis para a compreensão da natureza dedutiva das categorias, cuja pertinência não diz respeito à sua mobilização empírica, mas a seus fundamentos teóricos. Ainda que essa característica justifique, por um lado, as críticas à sua adequação a contextos particulares, por outro, ela garante sua aplicabilidade a situações radicalmente distintas.

\section{O desafio de codificar programas na América Latina}

O conjunto de dados reunidos pelo CMP-MARPOR possibilitou a análise empírica das principais relações políticas que compõem o debate internacional em Ciência Política. Atualmente, o "Mapping policy preferences II: estimates for parties, electors, and governments in Eastern Europe, European Union, and OECD 1990-2003" (BUDGE et al., 2006), que trata acerca do manifesto e da aplicabilidade dos dados, é citado por mais de 1.200 artigos referenciados no 
Google Scholar, publicações decorrentes de pesquisas que utilizam ou discutem a plataforma de dados do CMP-MARPOR.

Diante disso, acreditamos que a disseminação do método desenvolvido pelo CMP-MARPOR ofereça um caminho interessante para reforçar a dimensão comparativa das análises políticas aqui realizadas, tendo em vista a base de dados dos manifestos que abarca, sobretudo, países europeus. Daí nosso esforço ${ }^{13}$ em codificar e comparar os programas de governo dos principais candidatos à Presidência da República do Brasil nas eleições de 1989, 1994, 1998, 2002, 2014 e 2018. ${ }^{14}$

Não obstante, parte da literatura ainda questiona a pertinência da adoção do CMP-MARPOR para análises sobre a América Latina. No princípio, os próprios desenvolvedores da metodologia foram céticos acerca da proposta de ampliar sua aplicação para o contexto latino-americano (ARES; VOLKENS, 2017, p. 124). Parte das críticas à aplicação de uma metodologia, desenvolvida para o estudo de partidos políticos inseridos no contexto europeu, a uma realidade política diversa como a latino-americana seria a maior presença de relações alheias aos parâmetros normativos que estruturam as democracias liberais. Entre essas relações podemos citar o clientelismo e o populismo, ou seja, a prevalência de estratégias vote e office seeking sobre preocupações programáticas (policy seeking). Desse modo, especula-se acerca da incorporação de categorias capazes de abarcar esses dois fenômenos, especialmente formuladas para dar conta das singularidades da dinâmica política latino-americana.

Diante desse desafio, e tomando como base a experiência com partidos populistas europeus, optou-se pela aplicabilidade da metodologia à América Latina (ARES; VOLKENS, 2017, p. 124). Em face das primeiras análises, oriundas de sua aplicação ao caso mexicano, os desenvolvedores da metodologia concluíram que os resultados foram "promissores" (VOLKENS; BARA, 2013, p. 286-287). Contudo, eles alertam que é necessário ter cautela ao

13 Parte deste esforço pode ser conferido em JORGE et al., 2018.

14 Os programas de 2006 e 2010 já se encontravam no banco de dados do CMP-MARPOR. 
coletar e preparar os dados para a América Latina a partir das codificações já existentes. Esse foi o aprendizado desenvolvido ao analisar a extensão do banco de dados para a Central and Eastern Europe (CEE), ${ }^{15}$ que sugerem que deva ser adotada nas demais empreitadas.

A experiência de ampliação do escopo de análise para além das fronteiras iniciais (Leste Europeu e América Latina), contudo, provocou transformações na própria metodologia ${ }^{16}$. Isso porque, ao longo do processo de codificação de programas referentes às eleições de mais de 18 países latino-americanos ${ }^{17}$ incluídos na base de dados do CMP-MARPOR, optou-se por adaptar algumas das categorias existentes, além de usar subcategorias, com o propósito de ampliar o escopo analítico disponível aos codificadores de todo mundo, sem ultrapassar o balizador das 56 categorias iniciais.

Ao longo do tempo, foram modificadas inclusive as instruções de codificação e o esquema de categorias, com o intuito de permitir comparar e agregar os novos dados. Essas modificações estão detalhadas em cinco versões diferentes dos manuais. No documento Evolution of the "Manifesto coding instructions" and the category scheme, observa-se que a versão mais recente do manual adotou reformulações e adições para abarcar países da América Latina e

15 Alguns especialistas argumentaram, quando da experiência de codificação da CEE, que uma codificação totalmente diferente seria necessária para lidar com a política de uma região totalmente distinta das velhas democracias: uma região onde a democracia estava ainda aparecendo pela primeira vez em alguns países, e o populismo e o autoritarismo estariam não só presentes, mas fortalecidos (VOLKENS; BARA, 2013, p. 286).

16 Outro motivo dessas alterações foi a conformação com a nova realidade da União Europeia. Nesse primeiro desafio, foi necessária a ampliação do banco de dados, antes adotado apenas nacionalmente. A classificação dos partidos (party families) ampliou-se internacionalmente. Foram analisados comparativamente todos os partidos que alcançaram representação parlamentar em 80 eleições nacionais, nos 25 países membros da União Europeia no período 1990-2002. Desse modo, foram correlacionados os dados tanto dos antigos partidos da Europa Ocidental quanto dos novos partidos da Europa Central e Oriental (KLINGEMANN; BUDGE, 2013, p. 51).

17 O Manifesto Project está sendo estendido para a América Latina porque a base de dados não contava com um número suficiente de regimes presidenciais para se realizar estudos comparados entre democracias parlamentares e presidenciais. Atualmente, contudo, o CMP-MARPOR disponibiliza dados de seis países latino-americanos (Argentina, Bolívia, Brasil, Chile, México e Uruguai). Segundo Cristina Ares e Andrea Volkens, entre os objetivos prioritários do Projeto Manifesto está a extensão da base de dados até 2021 para outros 12 países dessa região Colômbia, Costa Rica, Dominicana, Equador, El Salvador, Guatemala, Honduras, Nicarágua, Panamá, Paraguai, Peru e Venezuela (ARES; VOLKENS, 2017, p. 118-119, 125, 127 e 128) 
tratar de candidatos à Presidência da República. A versão adotada atualmente é Manifesto coding instructions: $5^{\text {th }}$ fully revised edition (WERNER; LACEWELL; VOLKENS, 2015). ${ }^{18}$ As mudanças, em sua maior parte, dizem respeito à renomeação de categorias antigas e à inserção de novas subcategorias, sempre mantendo, como já mencionado, as 56 categorias iniciais. O objetivo dessas modificações era possibilitar que a metodologia contemplasse: $i$ ) as diferenças institucionais, em especial no tocante às competências conferidas ao Poder Executivo nacional nos países latino-americanos; ii) as características de seus processos de transição para a democracia; iii) a presença de valores liberais e democráticos na região; iv) a integração regional; v) a participação do Estado na economia; vi) a imigração; e vii) a proteção de povos originários. ${ }^{19}$

Volkens e Bara (2013, p. 287) recomendam que a adoção do quadro existente com as 56 categorias, e observadas as subcategorias sugeridas, deveria ser mantida em países-piloto subsequentes para buscar refletir as diferentes políticas nacionais que podem ser encontradas na América Latina, uma vez que a introdução de novas categorias dificultaria a comparação dos resultados com o restante do banco de dados. Reconhecendo a importância desses ajustes e do esforço dos coordenadores do CMP-MARPOR em favorecer a aplicação do método na região, nossa equipe optou por trabalhar com as categorias já existentes. Tal opção acabou por se transformar em uma singularidade, na medida em que as principais empreitadas análogas no país optaram por preencher eventuais lacunas na metodologia e recorreram à criação de novos códigos para favorecer sua adequação ao caso brasileiro. Estamos nos referindo aqui ao

18 As anteriores são: Manifesto coding instructions: 4th fully revised edition (WERNER; LACEWELL; VOLKENS, 2011), Manifesto coding instructions: 3rd fully revised edition (WERNER; VOLKENS, 2010); Manifesto coding instructions: 2nd revised edition (VOLKENS, 2002); e Manifesto coding instructions: 1st edition (VOLKENS, 2001). Todas as edições estão disponíveis em: https://manifesto-project.wzb. eu/information/documents/handbooks

19 Estamos nos referindo às categorias/subcategorias foreign financial influence (103.2), European Community/Union or Latin America integration: positive (108), freedom and human rights: positive (201), democracy (202), decentralization (301), political corruption (304), political authority: positive (305), nationalisation (413); immigrants: diversity (607.2), indigenous rights: positive (607.3) e indigenous rights: negative (608.3). 
trabalho de Rafael Machado Madeira e Gabriela da Silva Tarouco publicado em 2013. Em seu artigo, é apresentada uma interessante proposta de adequação da metodologia do CMP ao caso brasileiro, a partir da reformulação de algumas de suas categorias. Também nos diferenciamos do esforço realizado pelos autores no texto intitulado "Esquerda e direita no Brasil: uma análise conceitual" (MADEIRA; TAROUCO, 2011), no qual discutem as ressignificações das duas categorias no contexto do fim da ditadura militar brasileira. Embora relevante, essa iniciativa difere daquela que motivou a formação do nosso grupo de pesquisa, cujo propósito é inserir o Brasil em um rol de indicadores que propiciam a comparação com outros casos.

Nossa equipe, embora reconheça a pertinência dessas críticas e a existência de lacunas, acredita que o formato atual dos códigos adotados no CMP-MARPOR é suficiente para atender a alguns propósitos daqueles que almejam analisar o posicionamento ideológico dos partidos políticos, sobretudo no tocante à possibilidade de compará-los entre si e de acompanhar suas transformações ao longo do tempo. Ademais, acreditamos que seja possível adequá-lo às nuances regionais (sejam elas clientelistas, populistas e de outra natureza) sem que haja a necessidade de alterar as categorias já existentes. Até porque, qualquer alteração nas categorias limita aquela que é uma das principais qualidades desta ferramenta heurística que diz respeito à possibilidade de mobilizá-la para comparar contextos distintos e afastados no continuum espaço-tempo, utilizando, para isso, um extenso banco de dados já catalogados e disponibilizados na plataforma do grupo.

A opção por essa abordagem radica na perspectiva - compartilhada pelos membros da equipe - de que a América Latina, como muitos especialistas já argumentaram, não é um caso especial (VOLKENS; BARA, 2013, p. 288). Isso significa dizer que as diferenças superficiais que emergem entre continentes e países não afetam os fundamentos da política doméstica - eleições, campanhas, partidos políticos e decisões de voto -, mas que, a despeito das singularidades internas, esses fundamentos operam de maneira análoga por toda parte. 


\section{O caso brasileiro em perspectiva comparada}

Para que o leitor possa compreender como a codificação dos programas de governo nos ajuda a ter uma compreensão mais completa do sistema partidário brasileiro, vamos comentar brevemente sobre as posições dos partidos políticos brasileiros no eixo esquerda-direita, mensuradas mediante a aplicação da metodologia do CMP-MARPOR. Em seguida, iremos apresentar os resultados obtidos por esforços análogos em outros países da região.

O Gráfico 1 mostra o índice Rile resultante da análise dos programas de governo das coligações ou dos partidos políticos dos candidatos que disputaram a Presidência da República, entre 1989 e 2018 , e obtiveram mais de $5 \%$ dos votos no primeiro turno. ${ }^{20}$ Esse gráfico permite ver a posição ocupada por cada candidato ou partido em um pleito específico e a variação de um pleito para outro.

20 No caso dos sistemas presidencialistas, a metodologia do Comparative Manifesto Project requer que se analise o programa de governo dos candidatos que concorrem às eleições presidenciais e que obtiveram nas urnas $5 \%$ dos votos ou mais nas eleições para o Executivo nacional. Isso significa que o banco de dados disponibilizado pelo CMP-MARPOR só contempla os partidos políticos que atenderam esse critério. Todavia, o caso do PSDB na eleição de 2018 demonstra que esse critério não é adotado rigidamente pelo CMP-MARPOR. Naquele pleito, esse partido político obteve $4,76 \%$ dos votos válidos, logo, o programa de governo do candidato Aécio Neves não deveria ter sido analisado. Apesar disso, esse documento teve seu conteúdo analisado e o resultado está disponível na página do CMP-MARPOR. Supomos que a decisão de analisar o programa tucano foi tomada porque Neves obteve um percentual de votos muito próximo de $5 \%$. 
Gráfico 1 - A posição ideológica dos partidos políticos brasileiros nas eleições presidenciais de 1989 a 2018

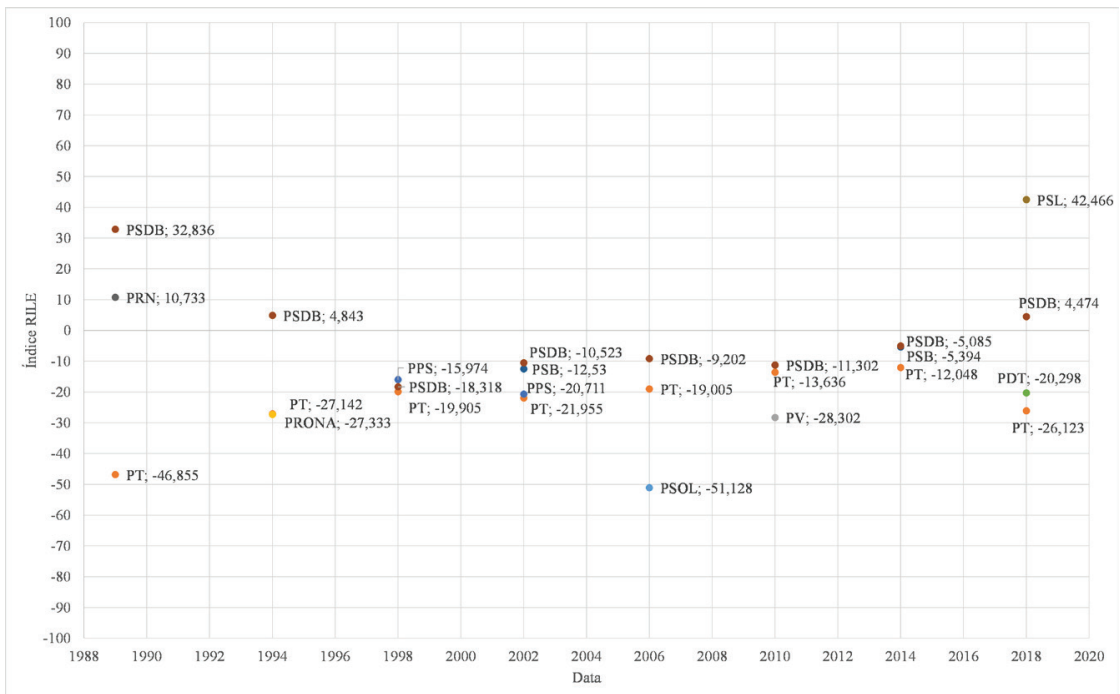

Fonte: CMP-MARPOR.

De acordo com o Gráfico 1, a metodologia do CMP-MARPOR indica que o Brasil só teve candidatos que assumiram propostas extremistas em três eleições, sendo estas, portanto, as mais polarizadas do nosso atual período democrático: os pleitos de 1989, 2018 e, em menor grau, o de 2006. Os programas de governo que continham conteúdo extremista (de esquerda ou de direita) foram os do candidato do Partido dos Trabalhadores - PT, Lula (1989); do Partido Socialismo e Liberdade - PSOL, Heloísa Helena (2006); e do Partido Social Liberal - PSL, Bolsonaro (2018). Desses, somente este último conseguiu o feito de ir para o segundo turno e se tornar presidente da República.

As demais eleições ocorridas entre 1989 e 2018, segundo o Gráfico 1, foram disputadas por coligações e partidos cujos candidatos defendiam propostas de esquerda, centro-esquerda, centro-direita ou de direita.

A metodologia do CMP-MARPOR aponta para uma oscilação no eixo esquerda-direita entre os dois principais rivais desse período: 0 
Partido da Social Democracia Brasileira - PSDB e o PT. ${ }^{21} \mathrm{O}$ candidato do PSDB defendeu propostas de direita em 1989, mas os que disputaram os pleitos posteriores assumiram outras posições: de esquerda (em 1998), centro-esquerda (de 2002 a 2014) e, por fim, de centro-direita (1994 e 2018). O candidato do PT, como já vimos, assumiu um projeto político de extrema-esquerda em 1989. Porém, nos demais pleitos, os candidatos petistas defenderam propostas mais moderadas: de esquerda (entre 1994 e 2006 e 2018) ou centro esquerda (em 2010 e 2014).

A metodologia do CMP-MARPOR, portanto, corrobora a percepção dos especialistas que localizam o PT na esquerda (HAGOPIAN; GERVASONI; MORAES, 2009; POWER; ZUCCO JR., 2009; ZUCCO JR., 2009; WIESEHOMEIER; BENOIT, 2009; LUCAS; SAMUELS, 2011; TAROUCO; MADEIRA, 2015; MACIEL; ALARCON; GIMENES, 2018; BOLOGNESI; BABIRESKI; MACIEL, 2019). Porém, dá mais nitidez a essa percepção porque é capaz de mostrar que esse partido ocupou diferentes posições no espaço entre a extrema-esquerda $(-45,855)$ e a centro-esquerda $(-12,048)$. A mesma nitidez também ocorre com relação ao PSDB. O índice Rile mostra que essa agremiação variou ao longo do eixo: foi da direita $(32,836)$ para a esquerda $(-18,318) .{ }^{22}$ Convém ressaltar que, mesmo quando ocupou uma posição de esquerda (eleição de 1998), o Gráfico 1 mostra que o PSDB esteve ligeiramente à direita do PT.

Chamou nossa atenção o índice Rile do programa de governo do candidato Enéas Carneiro (Partido de Reedificação da Ordem Nacional - Prona), que disputou a eleição presidencial de 1994. Embora o índice encontrado $(-27,333)$ indique ser este um candidato de "esquerda", há diversos trabalhos que afirmam que consideram esse partido de "direita" (CODATO; BERLATTO; BOLOGNESI, 2018; TAROUCO; MADEIRA, 2013a, 2013b; MAINWARING; MENEGUELLO; POWER, 2000; JORGE et al., 2018;

21 Dizemos que foram os principais porque os candidatos eleitos presidente da República entre 1994 e 2014 pertenciam a um desses dois partidos políticos.

22 Sobre a percepção dos especialistas, ver: CODATO; BELATTO; BOLOGNESI, 2018, p. 875. 
FERNANDES, 1995). O CMP-MARPOR, por sua vez, considera o Prona um partido nacionalista.

A divergência quanto à posição ideológica do Prona ocorreu porque os analistas encontraram no programa de governo do candidato desse partido político mais temas que o CMP-MARPOR identifica como sendo historicamente de esquerda $(44,21 \%)$ do que os considerados como sendo tipicamente de direita (16,87\%). ${ }^{23}$ Os temas de esquerda mais frequentes foram capturados por apenas quatro categorias, que correspondem a $36,46 \%$ de todas as quase-sentenças do programa de governo: 506. expansão da educação, 12,10\%; 504. expansão do estado de bem-estar, 14,05\%; 202.1 geral: positiva (democracia), 6,31\%; e 103.1. anti-imperialismo centrado no Estado, 4,0\%. Os temas de direita mais presentes, por sua vez, também foram capturados por apenas quatro categorias, que abrangem $10,61 \%$ da totalidade de quase-sentenças do documento: 603. moralidade tradicional: positiva, 2,92\%; 601.1. geral (estilo de vida nacional), 2,92\%; 305.3. autoridade política: governo forte, 2,41\%; e, por fim, 305.1. autoridade política: competência partidária, 2,36\%.

É plausível supor ainda que, ao localizar o Prona e Carneiro no campo da direita, os analistas estejam considerando outras evidências além do programa de governo do candidato e que abarcam fatos que ocorreram fora do período eleitoral. Estamos nos referindo aqui à participação do candidato em debates, declarações ou discursos feitos pelo candidato, à propaganda política do Prona nos meios de comunicação etc.

Apesar dessas considerações, acreditamos que uma explicação mais precisa para esse caso específico requer uma análise mais profunda que não pudemos realizar para este artigo.

Não obstante, de acordo com os propósitos deste artigo é fundamental ressaltar que nossa empreitada codificadora surge a partir do esforço, realizado pelo CMP-MARPOR, no tocante à ampliação do banco de dados para incluir os países da América Latina, 
realizado a partir de 2011. Em 2020, o projeto já disponibilizava 192 documentos referentes a seis países dessa região (Argentina, Bolívia, Brasil, Chile, México e Uruguai). O número e o período de abrangência dos dados, contudo, varia drasticamente de país para país. Enquanto, para o México, há 94 documentos de 1946 a 2015, para a Argentina, há 32 documentos que compreendem o período 2003 a 2013; para o Brasil, há 28 documentos produzidos entre 1989 e 2018; para o Chile, há 24 documentos com dados dos pleitos realizados entre de 1989 a 2017; para a Bolívia, há nove documentos com dados de 2009 a 2014; por fim, para o Uruguai, há cinco documentos com dados da eleição de 2014.

A expansão recente e os poucos dados disponibilizados pelo CMP-MARPOR talvez expliquem porque há uma escassez de trabalhos comparativos publicados. Em nossa pesquisa bibliográfica, encontramos somente dois artigos com este propósito que têm o Brasil como um dos casos. O primeiro trabalho é o artigo "Estimando el espacio político del Cono Sur y Brasil: las elecciones presidenciales en el eje izquierda-derecha" (LÓPEZ; MIRANDA; VALENZUELA-GUTIÉRREZ, 2013). Nesse trabalho, os autores utilizam a metodologia CMP-MARPOR para estudar a competição política comparando eleições presidenciais realizadas entre 2009 e 2011 em quatro países (Argentina, Brasil, Chile e Uruguai). Dessa forma, puderam estimar o posicionamento desses candidatos com respeito à principal dimensão da competição política (o eixo esquerda-direita) e suas localizações frente ao eixo mais Estado/ mais mercado e à dimensão justiça social e Estado de bem-estar (LÓPEZ; MIRANDA; VALENZUELA-GUTIÉRREZ, 2013, p. 429).

Em relação aos resultados, os autores perceberam que, de um modo geral, os candidatos a presidente dos quatro países tenderam a ocupar o centro do espectro político, sendo possível em alguns casos perceber uma leve tendência à direita (LÓPEZ; MIRANDA; VALENZUELA-GUTIÉRREZ, 2013, p. 423). A análise revelou que, no Brasil e no Chile, a metodologia empregada permitiu identificar quais eram os candidatos que se encontravam mais à esquerda (Marina Silva, no Brasil, e Arrate, no Chile) ou mais à direita (José Serra, no 
Brasil, e Piñera, no Chile) (LÓPEZ; MIRANDA; VALENZUELA-GUTIÉRREZ, 2013, p. 425-426). No Uruguai e na Argentina, isso não foi possível. Os autores constataram que todos os candidatos compartilharam o mesmo espaço político, mas a metodologia não permitiu verificar se algum deles situavam-se mais à esquerda ou mais à direita (LÓPEZ; MIRANDA; VALENZUELA-GUTIÉRREZ, 2013 , p. 430). Esses resultados foram corroborados por suas respectivas localizações ao longo dos eixos mais Estado-mais mercado e justiça social e Estado de bem-estar. Além disso, tornaram mais claro o perfil mais à direita de Piñera e o posicionamento mais à esquerda dos candidatos Mujica, Fernández e Rousseff (LÓPEZ; MIRANDA; VALENZUELA-GUTIÉRREZ, 2013, p. 431).

O segundo trabalho comparativo encontrado foi o artigo "As diferenças entre a direita do Brasil, Chile e Uruguai: análise dos programas e manifestos partidários", de Flávia Roberta Babireski (2014a). Com o propósito de identificar as diferenças nas abordagens e posicionamentos diante de alguns temas selecionados, Babireski analisou, utilizando a metodologia do CMP-MARPOR, o conteúdo de documentos de partidos políticos brasileiros, chilenos e uruguaios situados à direita no espectro ideológico. ${ }^{24} \mathrm{~A}$ análise demonstrou diferentes posicionamentos ao longo do eixo ideológico esquerda-direita. Enquanto os partidos políticos chilenos Unión Demócrata Independiente (UDI) e Renovación Nacional (RN) situaram-se mais à direita, o uruguaio Partido Nacional (PN) localizou-se mais ao centro, e os brasileiros Democratas (DEM) e Partido Progressista (PP) se posicionara mais à esquerda (BABIRESKI, 2014a, p. 184-185).

Embora Babireski não realize nenhuma adaptação da escala do CMP-MARPOR (BABIRESKI, 2014a, p. 179) como o fizeram Tarouco e Madeira (2013a, 2013b), os resultados obtidos pela pesquisadora não podem ser comparados com outras análises de

24 A autora utilizou, além dos programas de governo, manifestos e declarações de princípios de um partido político uruguaio (Partido Nacional - PN), de dois brasileiros (Democratas - DEM e Partido Progressista - PP) e de dois chilenos (Unión Demócrata Independiente - UDI e Renovación Nacional - RN). 
programas de governo. Isso porque essa pesquisadora incluiu, entre seus objetos de estudo, outros documentos (manifestos e declarações de princípios dos partidos políticos) além dos programas de governo. Daí a originalidade do nosso esforço de utilizar a metodologia do CMP-MARPOR sem incluir qualquer alteração, garantindo a comparabilidade das análises produzidas. Para tanto, sentimos falta, contudo, de mais pesquisas do gênero na América Latina, quer fornecendo informações programáticas para uma eleição específica, quer mostrando as mudanças entre um pleito e outro ao longo de uma série histórica.

\section{Conclusão}

Nossa principal intenção neste artigo foi discutir a metodologia desenvolvida pelo CMP-MARPOR enquanto estratégia para mensurar ideologias políticas a partir da análise de programas de governo. Esperamos, dessa forma, ter contribuído para o debate apresentando a metodologia ao público brasileiro e, simultaneamente, colaborando para reduzir a escassez de pesquisas que têm por objeto de estudo esses documentos produzidos pelos candidatos e seus respectivos partidos políticos.

Por serem manifestações públicas de candidatos e partidos políticos, os programas de governo podem ajudar a elucidar o posicionamento desses atores no sistema político. A metodologia desenvolvida pelo CMP-MARPOR considera que as avaliações e as propostas dos candidatos e/ou partidos políticos fornecem um meio para se identificar a posição que ele ocupa no eixo esquerda-direita na disputa eleitoral em questão. Para atingir esse objetivo, emprega-se o índice Rile, recurso que permite ao pesquisador posicionar a agremiação política e, consequentemente, seu candidato ao longo do referido eixo.

Nesse esforço, também começamos a refletir sobre os problemas e as vantagens da aplicação de uma métrica comum a um universo de casos marcado pela diversidade. Desse modo, embora reconheçamos a pertinência das críticas a essa metodologia, consideramos, ainda assim, que ela permite identificar o posicionamento 
ideológico dos partidos políticos latino-americanos e, em particular, dos brasileiros em uma campanha eleitoral. Essa opção indica que não consideramos nem o Brasil, nem a América Latina como casos excepcionais, cujas singularidades internas impediriam o uso de uma metodologia aplicável a outros países e regiões. Nossa intenção é justamente a de empregar tal metodologia para que seja possível inserir o Brasil em um rol de indicadores que propiciam a comparação com outros casos. Essa agenda de pesquisa tem em vista não apenas realizar comparações com contextos distintos e afastados no continuum espaço-tempo, mas também analisar as vantagens e os problemas do emprego do índice Rile em comparação com outras metodologias.

\section{Referências}

ADAMS, James; EZROW, Lawrence. Who do european parties represent? How western European parties represent the policy preferences of opinion leaders. The Journal of Politics, Chicago, v. 71, n. 1, p. 206-233, jan. 2009. Disponível em: https://www. jstor.org/stable/pdf/10.1017/s0022381608090130.pdf?seq=1. Acesso em: 25 jun. 2020.

AMORIM, Octavio. Gabinetes presidenciais, ciclos eleitorais e disciplina legislativa no Brasil. Dados, Rio de Janeiro, v. 43, n. 3, p. 479-519, 2000. Disponível em: http://www.scielo.br/scielo. php?script=sci_arttext\&pid=S0011-52582000000300003\&lng=p t\&nrm=iso. Acesso em: 25 jun. 2020.

ARES, Cristina; VOLKENS, Andrea. ¿Por qué y cómo se está extendiendo el Manifesto Project a América Latina?. Revista Española de Ciencia Política, n. 43, p. 115-135, mar. 2017. Disponível em: https://dialnet.unirioja.es/servlet/ articulo? codigo $=5920171$. Acesso em: 25 jun. 2020. 
BABIRESKI, Flávia. As diferenças entre a direita do Brasil, Chile e Uruguai: análise dos programas e manifestos partidários. Paraná Eleitoral, Curitiba, v. 3, n. 1, p. 171-198, abr. 2014 a. Disponível em: http://www.tre-pr.jus.br/o-tre/revista-paranaeleitoral/revistas-e-livros/revista-parana-eleitoral-v3n1. Acesso em: 25 jun. 2020.

BABIRESKI, Flávia. A direita no Brasil, Chile e Uruguai: estudo dos programas e manifestos partidários. 2014. 114 p. Dissertação (Mestrado em Ciência Política) - Universidade Federal do Paraná, Curitiba, 2014b. Disponível em: https://acervodigital. ufpr.br/handle/1884/41201. Acesso em: 25 jun. 2020.

BAIÃO, Alexandre Lima; COUTO, Cláudio Gonçalves; JUCÁ, Ivan Chaves. A execução das emendas orçamentárias individuais: papel de ministros, cargos de liderança e normas fiscais. Revista Brasileira de Ciência Política, Brasília, n. 25, p. 47-86, jan./abr. 2018. Disponível em: http://www.scielo.br/scielo. php?script=sci_arttext\&pid=S0103-33522018000100047\&lng $=$ p t\&nrm=iso. Acesso em: 25 jun. 2020.

BENOIT, Kenneth; MICHAEL, Laver; MIKHAYLOV, Slava. Treating words as data with error: uncertainty in text statements of policy positions. American Journal of Political Science, v. 53, n. 2, p. 495-513, abr. 2009.

BOBBIO, Norberto. Direita e esquerda. Razões e significados de uma distinção política. São Paulo: Unesp, 1995.

BOLOGNESI, Bruno; BABIRESKI, Flávia Roberta; MACIEL, Ana Paula. Conhecendo o vazio: congruência ideológica e partidos políticos no Brasil. Política \& Sociedade, Florianópolis, v. 18, n. 42, p. 86-116, maio/ago. 2019. Disponível em: https:// periodicos.ufsc.br/index.php/politica/article/view/21757984.2019v18n42p86. Acesso em: 25 jun. 2020.

BRAGA, Maria do Socorro Sousa. O processo político-partidário brasileiro e as eleições de 2006. Politica \& Sociedade, Florianópolis, v. 6, n.10, p. 53-90, abr. 2007. Disponível em: https://periodicos.ufsc.br/index.php/politica/article/view/1685. Acesso em: 25 jun. 2020. 
BUDGE, Ian; MEYER, Thomas. Understanding and validating the left-right scale (RILE). In: BUDGE, I. et al. (org.). Mapping policy preferences from texts: statistical solutions for manifesto analysts. Oxford: Oxford University Press, 2013, p. 85-106.

BUDGE, Ian et al. (org.). Mapping policy preferences from texts: statistical solutions for manifesto analysts. Oxford: Oxford University Press, 2013. 392 p.

BUDGE, Ian et al.. Mapping policy preferences II: estimates for parties, electors, and governments in Eastern Europe, European Union, and OECD 1990-2003. Oxford: Oxford University Press, 2006. v. 2.

BUDGE, Ian; LAVER, Michael. Office seeking and policy pursuit in coalition theory. Legislative Studies Quarterly, v. 11, n. 4, p. 485-506, nov. 1986. Disponível em: https://www.jstor.org/ stable/439930?seq=1. Acesso em: 25 jun. 2020.

CARREIRÃO, Yan. Representação política como congruência entre as preferências dos cidadãos e as políticas públicas. Opinião Pública, Campinas, v. 21, n. 2, p. 393-429, ago. 2015. Disponível em: https://www.scielo.br/scielo.php?script=sci_ issuetoc\&pid=0104-627620150002\&lng=pt\&nrm=iso. Acesso em: 23 jun. 2020.

CARREIRÃO, Yan. O sistema partidário brasileiro: um debate com a literatura recente. Revista Brasileira de Ciência Política, Brasília, n. 14, p. 255-295, maio/ago. 2014. Disponível em: http://www.scielo.br/scielo.php?script=sci_arttext\&pid=S010333522014000200255\&lng=pt\&nrm=iso. Acesso em: 25 jun. 2020.

CARREIRÃO, Yan. Ideologia e partidos políticos: um estudo sobre coligações em Santa Catarina. Opinião Pública, Campinas, v. 12, n. 1, p. 136-163, abr./maio. 2006. Disponível em: http:// www.scielo.br/scielo.php?script=sci_arttext\&pid $=$ S0104$62762006000100006 \& \operatorname{lng}=$ pt\&nrm=iso. Acesso em: 25 jun. 2020. 
CODATO, Adriano; BERLATTO, Fábia; BOLOGNESI, Bruno. Tipologia dos políticos de direita no Brasil: uma classificação empírica. Análise Social, Lisboa, v. LIII, n. 229, p. 870-897, dez. 2018.

DANTAS, Humberto; PRAÇA, Sérgio. Pequenos partidos no Brasil: uma análise do posicionamento ideológico com base nas coligações municipais de 2000 a 2008. In: KRAUSE, Silvana; DANTAS, Humberto; MIGUEL, Luis Felipe (org.). Coligações partidárias na nova democracia brasileira: perfis e tendências. Rio de Janeiro: Konrad-Adenauer Stiftung; São Paulo: Unesp, 2010. p. 325-343.

DIAS, Marcia Ribeiro; MENEZES, Daiane Boelhouwer; FERREIRA, Geison da Cunha. A quem serve o Graal? Um estudo sobre a classificação ideológica dos partidos políticos através de seus projetos de lei na Alergs (2003 a 2006). Civitas, Porto Alegre, v. 12, n. 2, p. 209-235, 2012.

DOWNS, Anthony. Uma teoria econômica da democracia. Tradução: Sandra Guardini Teixeira Vasconcelos. Sāo Paulo: EDUSP, 1999. 336 p.

FERNANDES, Luís. Muito barulho por nada? O realinhamento político-ideológico nas eleições de 1994. Dados, Rio de Janeiro, v. 38, n. 1, p.107-144, 1995.

FREIRE, André. Esquerda e direita na política europeia: Portugal, Espanha e Grécia em perspectiva comparada. Lisboa: ICS, 2006. FRANZMANN, Simon. From data to inference and back again: perspectives from content analysis. In: BUDGE, Ian et al. (org.). Mapping policy preferences from texts: statistical solutions for manifesto analysts. Oxford: Oxford University Press, 2013. p. 210-235.

GOMES, Fábio de Barros Correia. Produção legislativa no Brasil: visão sistêmica e estratégica no presidencialismo de coalizão. Brasília: Edições Câmara, 2013. 
HAGOPIAN, Frances; GERVASONI, Carlos; MORAES, Juan Andrés. From Patronage to program: the emergence of partyoriented legislators in Brazil. Comparative Political Studies, v. 42, n. 3, p. 360-391, mar. 2009.

JORGE, Vladimyr Lombardo et al. Análise dos programas eleitorais dos candidatos a presidente em 2014: o posicionamento ideológico do PT e do PSDB. Revista de Sociologia e Política, Curitiba, v. 26, n. 67, p. 1-20, set. 2018. Disponível em: http:// www.scielo.br/scielo.php?script $=$ sci_arttext\&pid $=$ S010444782018000300001\&lng=pt\&nrm=iso. Acesso em: 25 jun. 2020.

KINZO, Maria D’Alva. Os partidos no eleitorado: percepções públicas e laços partidários no Brasil. Revista Brasileira de Ciências Sociais, São Paulo, v. 20, n. 57, p. 65-81, fev. 2005. Disponível em: http://www.scielo.br/scielo.php?script=sci_ arttext\&pid=S0102-69092005000100005\&lng=pt\&nrm=iso. Acesso em: 25 jun. 2020.

KLINGEMANN, Hans-Dieter; BUDGE, Ian. Using the manifesto estimates to refine party family placements. In: BUDGE, Ian et al. (org.). Mapping policy preferences from texts: statistical solutions for manifesto analysts. Oxford: Oxford University Press, 2013. p. 49-65.

KNIGHT, Kathleen. Transformations of the concept of ideology in the twentieth century. American Political Science Review, v. 100, n. 4, p. 619-626, nov. 2006.

LAVAREDA, José Antônio. A democracia nas urnas: o processo partidário-eleitoral brasileiro (1945-1964). Rio de Janeiro: Rio Fundo; Iuperj, 1999.

LEONI, Eduardo. Coligações e ideologia nas eleições para vereador no Brasil. In: POWER, Timothy; ZUCCO JÚNIOR, Cesar (org.). O Congresso por ele mesmo: autopercepções da classe política brasileira. Belo Horizonte: Editora UFMG, 2011. 
LEONI, Eduardo. Ideologia, democracia e comportamento parlamentar: a Câmara dos Deputados (1991-1998). Dados, Rio de Janeiro, v. 45, n. 3, p. 361-386, 2002. Disponível em: http://www.scielo.br/scielo.php?script=sci_arttext\&pid=S0011$52582002000300002 \& \operatorname{lng}=$ pt\&nrm=iso. Acesso em: 25 jun. 2020.

LÓPEZ, Miguel Ángel; MIRANDA, Nicolás; VALENZUELAGUTIÉRREZ, Pablo A. Estimando el espacio político delConoSur y Brasil: las elecciones presidenciales en el eje izquierda-derecha. POSTData, Buenos Aires, v. 18, n. 2, p. 403-442, out. 2013. Disponível em: http://www.revistapostdata.com.ar/2013/10/ estimando-el-espacio-politico-del-cono-sur-y-brasil-laselecciones-presidenciales-en-el-eje-izquierda-derecha-miguelangel-lopez-nicolas-miranda-y-pablo-a-valenzuela-gutierrez/. Acesso em: 25 jun. 2020.

LUCAS, Kevin; SAMUELS, David. A “coerência” ideológica do sistema partidário brasileiro, 1990-2009. In: POWER, Timothy; ZUCCO JÚNIOR, Cesar. (org.). O Congresso por ele mesmo: autopercepções da classe política brasileira. Belo Horizonte: Editora UFMG, 2011.

MACIEL, Ana Paula Brito; ALARCON, Anderson de Oliveira; GIMENES, Éder Rodrigo. Partidos políticos e espectro ideológico: parlamentares, especialistas, esquerda e direita no Brasil. Revista Eletrônica de Ciência Política, Curitiba, v. 8, n. 3, p. 72-88, 2018. Disponível em: https://revistas.ufpr.br/politica/ article/view/54834. Acessado em: 25 jun. 2020.

MADEIRA, Rafael Machado; TAROUCO, Gabriela da Silva. Esquerda e direita no Brasil: uma análise conceitual. Revista Pós Ciências Sociais, São Luís, v. 8, n. 15, p. 171-185, jan./jun. 2011. Disponível em: http://www.periodicoseletronicos.ufma. br/index.php/rpcsoc/article/view/591. Acesso em: 23 jun. 2020. MAINWARING, Scott. Políticos, partidos e sistemas eleitorais: o Brasil numa perspectiva comparada, Novos Estudos Cebrap, São Paulo, n. 29, p. 34-58, mar. 1991. 
MAINWARING, Scott; MENEGUELLO, Rachel; POWER, Timoty. Partidos conservadores no Brasil contemporâneo. Tradução: Valéria Carvalho Power. São Paulo: Paz e Terra, 2000.

MEDEIROS, Neuci Pimenta de. A influência da ideologia partidária na formalização de orçamentos participativos no Brasil. 2018. 220 p. Tese (Doutorado em Ciência Política) Instituto Universitário de Lisboa, Lisboa, 2018. Disponível em: https://repositorio.iscte-iul.pt/handle/10071/17182. Acesso em: 25 jun. 2020.

MELO, Carlos Ranulfo. Avaliando vínculos entre partidos e deputados nas assembleias legislativas brasileiras. Opinião Pública, Campinas, v. 21, n. 2, p. 365-392, ago. 2015. Disponível em: http://www.scielo.br/scielo.php?script=sci_ arttext\&pid=S0104-62762015000200365\&lng=pt\&nrm=iso. Acesso em: 25 jun. 2020.

MELO, Carlos Ranulfo; CÂMARA, Rafael. Estrutura da competição pela presidência e consolidação do sistema partidário no Brasil, Dados, Rio de Janeiro, v. 55, n. 1, p. 71-117, 2012. Disponível em: http://www.scielo.br/scielo.php?script=sci_arttext\&pid=S001152582012000100003\&lng=pt\&nrm=iso. Acesso em: 25 jun. 2020.

MELO, Marcus André. Controle do Poder Executivo e presidencialismo de coalizão. Cadernos Aslegis, n. 40, p. 55-78, maio/ago. 2010. Disponível em: https://www.aslegis.org. br/files/cadernos/2010/Caderno40/07_controle_do_poder_ executivo_e_presidencialismo_de_coalizao.pdf. Acesso em: 25 jun. 2020.

OLIVEIRA, Carlos; TURGEON, Mathieu. Ideologia e comportamento político no eleitorado brasileiro. Opinião Pública, Campinas, v. 21, n. 3, p. 574-600, set./dez. 2015. Disponível em: http://www.scielo.br/scielo.php?script=sci_ arttext\&pid=S0104-62762015000300574\&lng=pt\&nrm=iso. Acesso em: 25 jun. 2020. 
POWER, Timothy; ZUCCO JR., Cesar. Estimating ideology of Brazilian legislative parties, 1990-2005: a research communication. Latin American Research Review, v. 44, n. 1, p. 218-246, 2009. Disponível em: https://www.jstor.org/stable/ i20488164. Acesso em: 25 jun. 2020.

RIBEIRO, Ednaldo A.; BOLOGNESI, Bruno. Ideologia e representação: valores e atitudes dos legisladores municipais. In: GIMENES, Éder Rodrigo; BORBA, Julian. (org.). Poder legislativo e cultura política: valores, atitudes, trajetória e comportamento político dos vereadores e vereadoras do Estado de Santa Catarina. Curitiba: CPOP 2018, p. 131-181.

ROBERTSON, David. A theory of party competition. New York: Wiley, 1976.

RODRIGUES, Leôncio Martins. Partidos, ideologia e composição social. Revista Brasileira de Ciências Sociais, São Paulo, v. 17, n. 48,p.31-47,fev.2002a.Disponívelem:http://www.scielo.br/scielo. php? script=sci_arttext\&pid=S0102-69092002000100004\&lng $=$ p t\&nrm=iso. Acesso em: 25 jun. 2020.

RODRIGUES, Leôncio Martins. Partidos, ideologia e composição social: um estudo das bancadas partidárias na Câmara dos Deputados. São Paulo: Edusp, 2002 b.

SCHEEFFER, Fernando. Ideologia e comportamento parlamentar na Câmara dos Deputados. Teoria \& Pesquisa, São Carlos, v. 27, n. 2, p. 167-188, 2018. Disponível em: http://www. teoriaepesquisa.ufscar.br/index.php/tp/article/view/670. Acesso em: 25 jun. 2020.

SHALDERS, André. Direita ou esquerda? Análise de votações indica posição de partidos brasileiros no espectro ideológico. BBC BRASIL, São Paulo, 11 set. 2017. Disponível em: https:// www.bbc.com/portuguese/brasil-41058120. Acesso em: 26 fev. 2020. 
SILVA, Thiago Moreira da. Para além de esquerda e direita: a multidimensionalidade das crenças no Brasil contemporâneo (1989-2014). 2017. 182 p. Tese (Doutorado em Ciência Política) - Universidade de Brasília, Brasília, 2017. Disponível em: https:// repositorio.unb.br/handle/10482/32005. Acesso em: 25 jun. 2020.

SINGER, André. Esquerda e direita no eleitorado brasileiro. São Paulo: Edusp; Fapesp, 2000.

STROM, Kaare. A behavioral theory of competitive political parties. American Journal of Political Science, Austin, v. 34, n. 2, p. 565-598, maio 1990. Disponível em: https://www.jstor.org/ stable/2111461? seq=1. Acesso em: 25 jun. 2020.

TAROUCO, Gabriela da Silva; MADEIRA, Rafael Machado. Os partidos brasileiros segundo seus estudiosos: análise de um expert survey. Civitas, Porto Alegre, v. 15, n. 1, p. 24-39, jan./mar. 2015. Disponível em: http://www.scielo.br/scielo. php?script=sci_arttext\&pid=S1519-60892015000100140\&lng=e n\&nrm=iso. Acesso em: 25 jun. 2020.

TAROUCO, Gabriela da Silva; MADEIRA, Rafael Machado. Esquerda e direita no sistema partidário brasileiro: análise de conteúdo de documentos programáticos. Revista Debates, Porto Alegre, v. 7, n. 2, p. 93-114, maio/ago. 2013a. Disponível em: https://seer.ufrgs.br/debates/article/view/38573. Acessado em 25 jun. 2020.

TAROUCO, Gabriela da Silva. Partidos, programas e o debate sobre esquerda e direita no Brasil. Revista de Sociologia e Política, Curitiba, v. 21, n. 45, p. 149-165, mar. 2013b. Disponível em: http://www.scielo.br/scielo.php?script=sci_arttext\&pid=S0104$44782013000100011 \& \operatorname{lng}=$ pt\&nrm=iso. Acesso em: 25 jun. 2020.

WERNER, Annika; VOLKENS, Andrea; LACEWELL, Onawa. Manifesto coding instructions: 5th fully revised edition. Berlin: Wissenschaftszentrum Berlin für Sozialforschung, 2015. Disponível em: https://manifesto-project.wzb.eu/information/ documents/handbooks. Acesso em: 20 mar. 2017. 
WERNER, Annika; VOLKENS, Andrea; LACEWELL, Onawa. Manifesto coding instructions: 4th fully revised edition. Berlin: Wissenschaftszentrum Berlin für Sozialforschung, 2011. Disponível em: https://manifesto-project.wzb.eu/information/ documents/handbooks. Acesso em: 20 mar. 2017.

WERNER, Annika; VOLKENS, Andrea. Manifesto coding instructions: 3rd fully revised edition. Berlin: Wissenschaftszentrum Berlin für Sozialforschung, 2010. Disponível em: https://manifesto-project.wzb.eu/information/ documents/handbooks. Acesso em: 20 mar. 2017.

VOLKENS, Andrea. Manifesto coding instructions: 2nd revised edition. Berlin: Wissenschaftszentrum Berlin für Sozialforschung, 2002. Disponível em: https://manifesto-project. wzb.eu/information/documents/handbooks. Acesso em: 20 mar. 2017.

VOLKENS, Andrea. Manifesto coding instructions: 1st edition. Berlin: Wissenschaftszentrum Berlin für Sozialforschung, 2001. Disponível em: https://manifesto-project.wzb.eu/information/ documents/handbooks. Acesso em: 20 mar. 2017.

VOLKENS, Andrea; BARA, Judith. Presidential versus parliamentary representation: extending the manifesto estimates to Latin America. In: BUDGE, Ian et al. (org.). Mapping policy preferences from texts: statistical solutions for manifesto analysts. Oxford: Oxford University Press, 2013. p. 277-298.

WIESEHOMEIER, Nina; BENOIT, Kenneth. Presidents, Parties and Policy Competition. Journal of Politics, Chicago, v. 71, n. 4, p. 1435-1447, Oct. 2009. Disponível em: https://www.jstor.org/ stable/10.1017/s0022381609990193?seq=1. Acesso em: 25 jun. 2020.

ZUCCO JR., César. Esquerda, direita e governo: a ideologia dos partidos políticos brasileiros. In: POWER, Timothy; ZUCCO JÚNIOR, Cesar (org.). O Congresso por ele mesmo: autopercepções da classe política brasileira. Belo Horizonte: Editora UFMG, 2011, p. 37-60. 
ZUCCO JR., César. Ideology or what? Legislative behavior in multiparty presidential settings. Journal of Politics, Chicago, v. 71, n. 3, p. 1076-1092, jul. 2009. Disponível em: https://www. jstor.org/stable/10.1017/s0022381609090896?seq=1. Acesso em: 25 jun. 2020.

\section{Resumo}

O presente artigo é uma nova contribuição ao debate acerca da ideologia dos partidos políticos brasileiros, formulada com o intuito de adensar a discussão metodológica sobre o tema. Com esse propósito, faremos uma revisão da bibliografia internacional acerca da metodologia elaborada pelo Comparative Manifesto Project (CMP-MARPOR) para analisar quantitativamente programas de governo, discutindo suas transformações ao longo do tempo, bem como seu processo de adaptação e expansão para a América Latina. Em seguida, iremos apresentar o índice RILE, criado para mensurar a localização de partidos políticos na escala esquerdadireita, refletindo sobre sua aplicabilidade ao contexto brasileiro, no qual a ideologia surge como resultante do processo de formação de coalizões. Por fim, demonstrando a hipótese acerca da utilidade da metodologia por nós escolhida, iremos apresentar os resultados obtidos através de sua aplicação, mapeando o posicionamento dos principais partidos políticos brasileiros e observando sua movimentação da escala ideológica ao longo de todas as eleições presidenciais realizadas no Brasil sob a égide da Constituição de 1988.

Palavras-chave: Comparative Manifesto Project, Eleições, Ideologia, Índice RILE, Partidos Políticos, Comportamento Político.

\section{Abstract}

This article is a new contribution to the debate about Brazilian political party ideology, written with the intention of deepening methodological discussion on the subject. To this end, we will review the international literature on the methodology developed by the Comparative Manifesto Project (CMP-MARPOR) for the quantitative analysis of government programs, discussing its transformation over time, as well as the adaptation and expansion in Latin America. Next, we will present the RILE index, created as an estimate of the left-right positioning of political parties, reflecting on its applicability to the Brazilian context, where ideology 
emerges as a result of coalition formation. Finally, to demonstrate the usefulness of the methodology we have chosen, we will present the results obtained through its application, mapping the positioning of the main Brazilian political parties and observing their movement on the ideological scale over the course of presidential elections held in Brazil since the 1988 Constitution.

Keywords: Comparative Manifesto Project, Elections, Ideology, RILE index, Political Parties, Political Behavior.

Recebido em 20 de agosto de 2019 Aprovado em 20 de junho de 2020 